\title{
A Bibliometrics study on homework from 1977 to 2020
}

\author{
Phan Thi Thanh Thao', Nguyen Yen $\mathrm{Chi}^{2}$, \\ Hoang Anh Duc ${ }^{3}$
}

\author{
${ }^{1}$ Reducation Research Group, Thanh Do University \\ Email: phanthao@thanhdouni.edu.vn \\ ${ }^{2}$ EdLab Asia Educational Research and Development Centre \\ Email: chi@edlabasia.org \\ ${ }^{3}$ RMIT University \\ Email: duc@edlabasia.org
}

\begin{abstract}
Homework effectiveness has long been a controversial issue for many educators, schools, and parents. Many researchers have tried to prove that homework is not just a nuisance we all have to face throughout the years but really can build character and good for students, like teachers and parents typically say. This bibliometrics review studied 429 documents related to homework in education from the Clarivate Web of Science from 1977 to 2020. This study aims to record the volume, growth pattern of homework literature and identify critical authors, publications, and topics of this knowledge base. The review found that the homework literature has grown remarkably over the past 43 years, with the most cited authors are from the US, Germany, and Portugal. Using co-citation, co-occurrence and bibliographic coupling analysis from the VOSviewer program, this research also indicated significant results and suggestions for future research. The findings showed that homework literature increased gradually in volume, with the most publications originated in the USA, and critical authors were Cooper, Xu, and Trautwein. Additionally, five common research topics were illustrated, namely the effect of homework and its measurement, homework environment, homework tasks and feedback, family involvement in homework, and time and effort.
\end{abstract}

KEYWORDS: Bibliometrics, review, homework, teachers, parents.

$\Rightarrow$ Received 02/7/2021 $\rightarrow$ Revised manuscript received 28/7/2021 $\rightarrow$ Accepted 31/7/2021.

\section{Introduction}

Education is one of the keys to facilitating many Sustainable Development Goals (Vuong, 2018; Hoang et al., 2020). In order to improve education, we need to change various variables in education function. Among those variables, homework plays an important role. Homework has been proved to form and build students' learning habits and skills as well as intrinsic motivation (Otto, 1985; Cooper, 1994; Tran et al., 2020). Moreover, homework can foster relationships amongst family members, between students and teachers, and at the same time, promote the art of teaching. The modern era even witnesses a new role for homework as a form of social communication and contact among peers; since homework is an activity in which the whole class can participate, discuss and work together, it increases a sense of community (Corno, 2000). Therefore, homework has a prominent place in increasing a sense of community, which is crucial in bringing students together to work collectively for the group, and developing natural, collaborative communities. Additionally, homework is "a bridge for knowledge to travel back and forth between school and home" (Corno, 2000, p. 533). All considered, if homework is the lever that possibly moves education (and even society and culture-related issues), then where is the fulcrum: in the curriculum, parental involvement, teachers' feedback, or in the students themselves?

Cooper (1989) defined homework as "tasks assigned to students by teachers that are meant to be carried out during non-school hours" (p.7). Homework excludes (i) guided study at school, (ii) home study courses via email, television or the Internet, and (iii) extracurricular activities, such as sports or students' participation in clubs after school (Cooper et al., 2006). 
Homework has always been a perennial educational issue (Marzano \& Pickering, 2007; Baş et al., 2017). This claim is evident in the U.S., where most educators believed homework was beneficial for a disciplined mind. Those beliefs stood until the 1940s when there were concerns over the pressure of homework on their children (Marzano \& Pickering, 2007). After that, Russia's launch of the Sputnik satellite reversed homework's negative attitudes as Americans thought their education had a shortfall; thus, more homework was assigned to students. Until now, the attitudes towards homework in the U.S. continue to be cyclical (Gill \& Schlossman, 2000).

The homework literature can be divided into five main topics: (i) homework time (time spent on homework) and academic achievement; (ii) homework and student attitudes; (iii) homework tasks, marking, and feedback; (iv) parental involvement in homework (how parents involve in their children's homework); (v) and the homework environment (the environment where students complete homework) (Sharp et al., 2001). Meanwhile, in a review study, Cooper (1989) reports three types of research regarding homework's effects: (i) comparison between achievements of students given homework and those given no homework; (ii) comparison between homework and in-class study; and (iii) relationship between students' time spent on homework and students' achievement. From another perspective, the literature can be clustered into two main viewpoints: for and against homework (Marzano \& Pickering, 2007).

Students around the world spend a considerable amount of time on homework. In the United States, research shows that students spent $20 \%$ of their academic time doing homework (Cooper, 1994). In addition to Cooper's research, an OECD's report indicated that, on average, a student (of OECD countries) spent 5.9 hours per week on homework, and this number declined to 4.9 hours in 2012 (OECD, 2014). Korean and Finnish students reported spending less than three hours per week doing homework (OECD, 2014). Meanwhile, students in Italy, Romania, Singapore, Russian Federation, Ireland and Kazakhstan claimed that they spent at least seven hours per week, on average, doing homework (OECD, 2014). With respect to students in Shanghai-China, the hours spent on homework climbed to 14 hours (OECD, 2014).

Considering that homework accounts for a large part of students' lives, research on homework and training teachers on homework has been minimal (Cooper et al., 2006; Hallam \& Rogers, 2018). Furthermore, research results have not been used to establish homework policies and practices in real life (Cooper et al., 2006). Additionally, regarding the review or bibliometric study on education, most of the up-to-date research has focused on a specific theme or topic, such as online versus traditional homework (Magalhães et al., 2020), parental involvement in homework (Walker et al., 2004) or the homework-achievement relation (Trautwein, 2007). Therefore, there is a shortage of review and bibliometric studies on homework and a need for a new synthesis of the homework literature (Cooper et al., 2006). Our study analyses 429 documents from 1977 to 2020 to have a general perspective on homework literature. This study will address the following research questions:

- RQ1. What is the overall volume, growth trajectory and distribution of publications across countries and journals?

- RQ2. What are the key authors and publications on homework research?

- RQ3. What are the most popular research topics in homework literature among different periods?

\section{Methodology}

\subsection{Identification of Sources}

\section{Data Source and the Search Process}

The authors implemented a search on the Clarivate Web of Science (WOS), one of the most qualified indexed databases for scientific research (Li et al., 2018). Covering more than 250 disciplines in science, social sciences and humanities (Cretu \& Morandau, 2020), WOS has become the world's leading analytical information platform and has been employed in thousands of academic documents during the last 20 years (Li et al., 2018). For instance, WOS has been increasingly used by policymakers and 
academic researchers in several countries, such as Vietnam (Vuong et al., 2019). As a result, the authors selected WOS as the primary data source for this study.

The PRISMA (Preferred Reporting Items for Systematic Reviews and Meta-Analyses) (Moher et al., 2010) was employed as guidelines for conducting systematic reviews of research (see Figure 1). In the first step of PRISMA, the authors entered the search query as follow:

(TI="homework"”) AND LANGUAGE: (English) AND DOCUMENT TYPES: (Article)

On the $7^{\text {th }}$ of October 2020, this search yielded a total of 824 articles covering various categories and all feasible publication years. Then, the categories were restricted to only education and some close-related education fields, namely: Education Educational Research, psychology educational, education science disciplines, education special, social work, humanities multidisciplinary, psychology multidisciplinary, psychology developmental, social issues, sociology, linguistics, family studies, area studies, social sciences interdisciplinary, Asian studies, behavioural sciences, psychology, language linguistics, psychology experimental, cultural studies, psychology social, psychology applied, urban studies.

After this step, 590 documents were retained, and ten more documents were dropped because of duplicates. With 580 articles left, the titles and abstracts were examined and read carefully by two authors in two rounds to determine topical relevance. For example, some articles were eliminated as their foci were on "homework therapy", "listening skill”, "emotion regulation", "chemistry major", "gender difference", or other topics that did not belong to "homework". Moreover, 22 articles with ambiguous titles and no abstract were also deleted from our list. Finally, 429 documents were included in the quantitative analysis process. The PRISMA details can be seen in Figure 1 below.

\subsection{Data Extraction and Analysis}

\subsubsection{Disambiguate Similar Terms and Names}

The authors downloaded data of 580 documents in both excel files and plaintext files from the WOS website. Data included the article title, author name, keyword, abstract, author address,
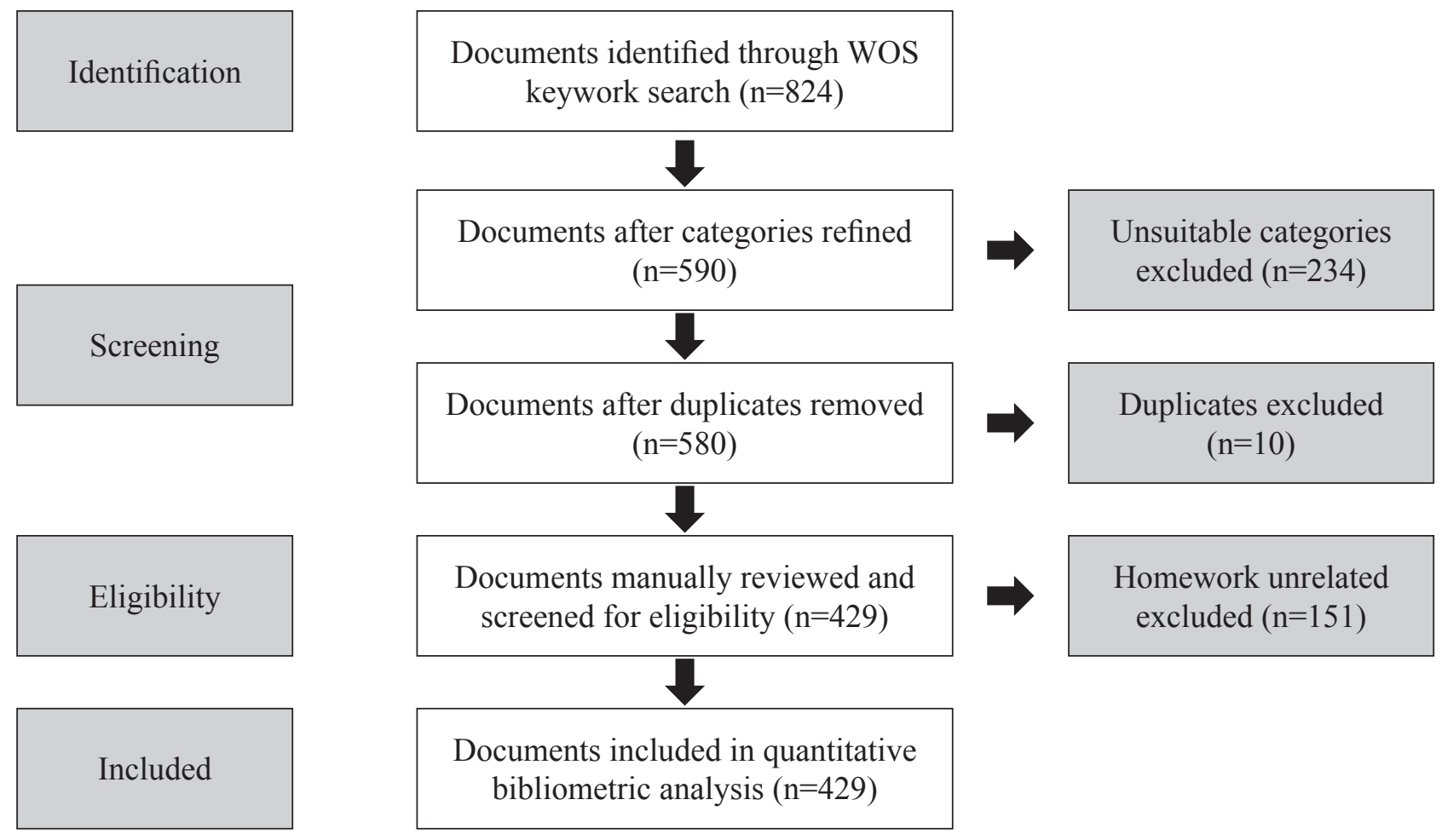

Figure 1: Preferred Reporting Items for Systematic Reviews and Meta-Analyses (PRISMA) flow diagram detailing the procedure to identify and screen homework databases 
reference, publisher, and other information. The authors thereupon manually read and eliminated illegible documents in the excel file, then replicated that process with the plaintext file. In addition to the excel file and plaintext file, the authors used a thesaurus file to reduce ambiguous and similar terms, thus the results' quality would be higher (Hallinger \& Chatpinyakoop, 2019). The reason for this was because the same scholar authored some documents but the names listed were different. Specifically, in the plaintext file, author Jianzhong $\mathrm{Xu}$ was listed as both $\mathrm{Xu} \mathrm{J}$. and $\mathrm{Xu} \mathrm{J.Z.} \mathrm{Therefore,} \mathrm{without} \mathrm{the} \mathrm{thesaurus}$ file, the analysis software would be misguided. Keywords also have the same problem, such as "secondary school" and "secondary schools", so using this thesaurus file will help VOSviewer elevate the final results' significance.

\subsubsection{Methods and Tools Used}

Quantitative data analysis was implemented by Excel, RStudio (Biblioshiny package) and VOSviewer version 1.6.15 to answer research questions number one, two, and three, respectively. Excel is a user-friendly and convenient tool, especially in creating bar graphs. Biblioshiny is a web-based application integrated within the bibliometric package and is used to perform bibliometric analysis (for example, co-citation, coupling, scientific collaboration analysis) (Aria \& Cuccurullo, 2017). Similarly, VOSviewer can also perform bibliometric analysis like Biblioshiny but has some advantages and disadvantages. In this study, the authors took advantage of VOSviewer to execute the co-word analysis.

\section{Descriptive Results}

\subsection{Volume, Growth Trajectory, and Distribution}

Figure 2 above divides research on homework into three stages. The first stage was from 1977 to 1993 . During this stage, the number of

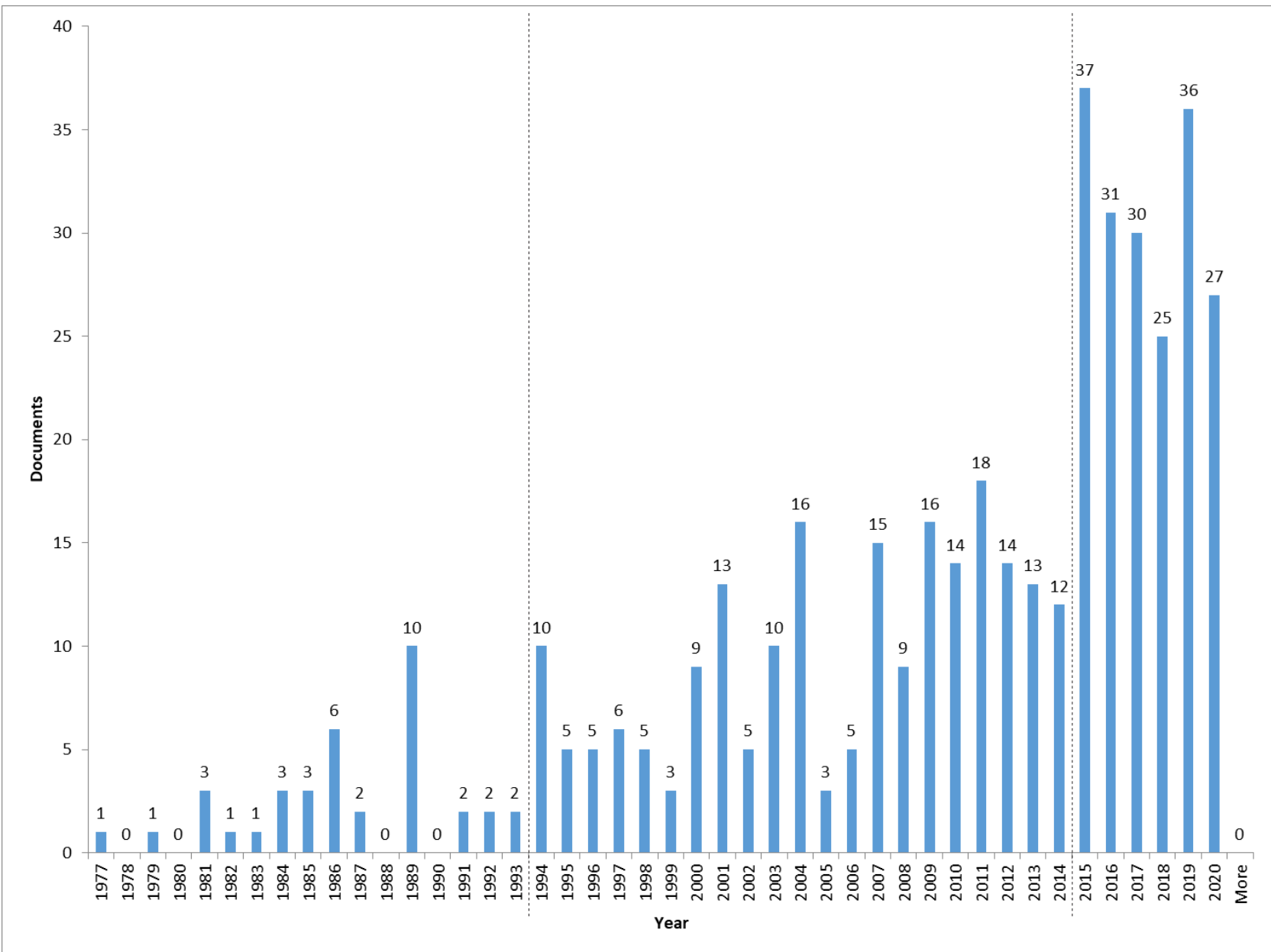

Figure 2: Publications by year 
publications was small and discrete, with only 37 documents published in total. The second stage from 1994 to 2014 witnessed a steady growth with at least three published documents each year, and the highest productivity was in 2011 with 18 documents. The final stage from 2015 to 2020 was a remarkable period, with the number of documents soared to 37 in 2015 and no less than 25 documents for other years. This movement suggested that research on homework gradually becomes foci among various educational sectors.

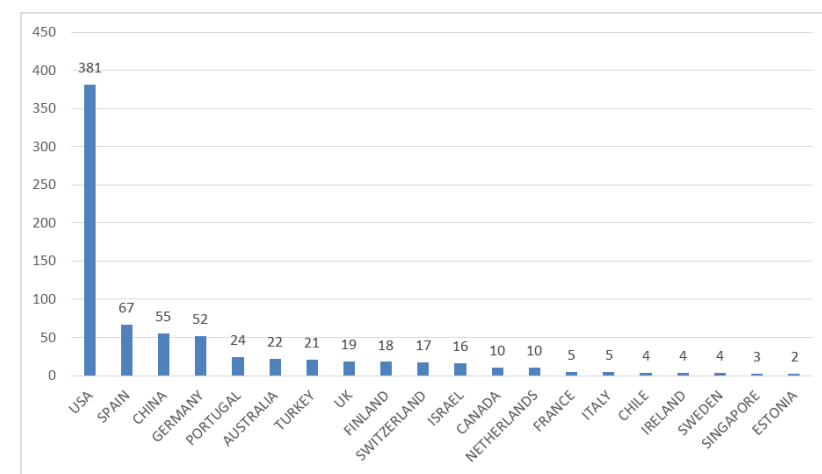

Figure 3: Distribution of publications across countries

Figure 3 above illustrates the geographic distribution of homework literature. However, this research did not count the documents regarding the first author's nationality. One document could contribute to various countries as long as its authors were from those countries. Notably, about half of the homework literature was from the United States, followed by Spain, China, Germany and Portugal. The rest of the top 20 countries spread from America (Canada, Chile), Europe (UK, Finland, Switzerland), Asia (Israel, Singapore, Turkey), and Australia (Australia). While 429 documents were authored in 33 countries, the above 20 countries accounted for roughly $97 \%$ of the corpus.

Nevertheless, the countries which had the most cited documents on homework reflected a different trend. Although the United States was still in the first place with 5539 citations, four countries that followed were different, namely Germany (1379 citations), Australia (392 citations), Israel (306 citations), and Spain (287 citations). The reader should note that China could not get into the top five, while Israel published only 16 articles yet got cited 306 times.

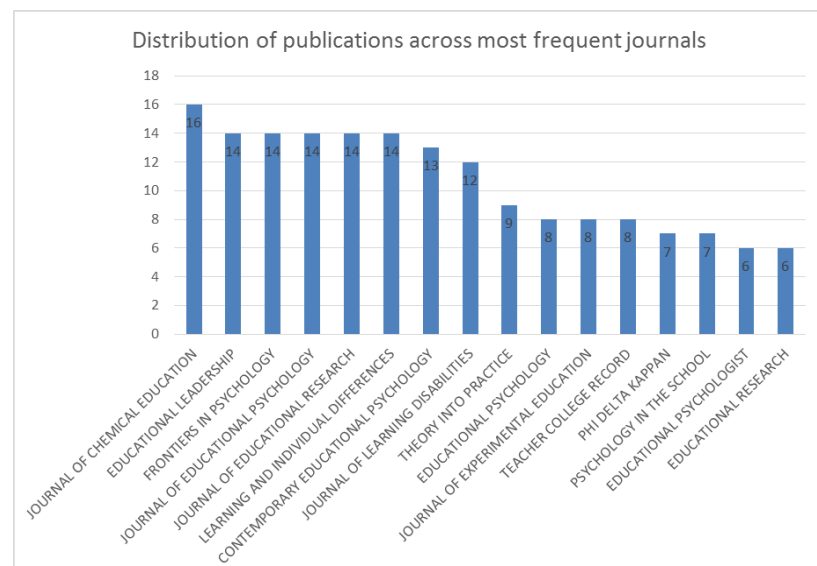

Figure 4: Distribution of the most frequent sources of literature on homework

In addition to the geographic distribution, this study provides the source distribution of homework literature (see Figure 4). Particularly, the journals which published homework articles were mainly education and psychology-related journals. The journals specializing in teaching and learning seemed not productive during this period. Among 176 journals which had published homework articles, these 16 journals (in Figure 4) accounted for nearly $40 \%$ of the total publications. Also, the top five sources which had the most cited homework documents were mainly related to psychology. In particular, they were Journal of Educational Psychology (1094 citations), Educational psychologist (812 citations), Contemporary Educational Psychology (749 citations), Journal of Educational Research (460 citations), and Learning and Individual Differences (368 citations). Notably, although Educational Psychologist ranked $15^{\text {th }}$ in the document numbers, it ranked second in the citation times; hence the journal quality can be reflected well in the total citation numbers.

\subsection{Influential Authors and Documents}

To find out the most influential authors and documents within this collection, we use citation analysis and co-citation analysis by Biblioshiny package (in RStudio). The results are presented in Table 1 and Table 2.

The most cited author was Cooper, with 676 citations over eight documents; on average, there 


\section{Table 1: Most highly-cited authors}

\begin{tabular}{|c|c|c|c|c|c|c|}
\hline Rank & Author & Institutional Affiliation(s) & Country & $\begin{array}{l}\text { Total } \\
\text { Docs }\end{array}$ & $\begin{array}{l}\text { Total } \\
\text { citations }\end{array}$ & $\begin{array}{l}\text { Citations per } \\
\text { documents }\end{array}$ \\
\hline 1 & COOPER H & Univ Missouri & USA & 8 & 676 & 84.5 \\
\hline 2 & $X U J Z$ & Columbia Univ; Mississippi State Univ & USA & 46 & 617 & 13.4 \\
\hline 3 & TRAUTWEIN U & $\begin{array}{l}\text { Univ Tubingen; Max Planck Inst } \\
\text { Human Dev }\end{array}$ & Germany & 20 & 437 & 21.9 \\
\hline 4 & CORNO L & Columbia Univ & USA & 5 & 223 & 44.6 \\
\hline 5 & EPSTEIN JL & Johns Hopkins Univ & USA & 4 & 174 & 43.5 \\
\hline 6 & HOOVER DEMPSEY KV & Vanderbilt Univ & USA & 1 & 128 & 128.0 \\
\hline 7 & KEITH TZ & Univ Texas & USA & 3 & 123 & 41.0 \\
\hline 8 & ZIMMERMAN BJ & CUNY City University of New York & USA & 2 & 109 & 54.5 \\
\hline 9 & NUNEZ JC & Univ Minho & Portugal & 17 & 103 & 6.1 \\
\hline 10 & ROSARIO P & Univ Minho & Portugal & 17 & 98 & 5.8 \\
\hline 11 & WARTON PM & Macquarie Univ & Australia & 2 & 93 & 46.5 \\
\hline 12 & POMERANTZ EM & Univ Illinois & USA & 1 & 91 & 91.0 \\
\hline 13 & DETTMERS S & Max Planck Inst Human Dev & Germany & 5 & 84 & 16.8 \\
\hline 14 & HONGE & Univ Nevada & USA & 4 & 83 & 20.8 \\
\hline 15 & PATALL EA & Univ Texas Austin & USA & 1 & 63 & 63.0 \\
\hline 16 & KATZ I & Ben Gurion Univ Negev & Israel & 8 & 59 & 7.4 \\
\hline 17 & BRYAN T & Arizona State Univ & USA & 4 & 55 & 13.8 \\
\hline 18 & VALLE A & Univ A Coruna & Spain & 1 & 52 & 52.0 \\
\hline 19 & FERNANDEZ ALONSO R & Univ Oviedo & Spain & 3 & 49 & 16.3 \\
\hline 20 & DUMONT H & German Inst Int Educ Res & Germany & 3 & 43 & 14.3 \\
\hline
\end{tabular}

were 84.5 citations per document. The highest citations per document belonged to Hoover with 128 citations, although the author wrote only one document. This remarkable phenomenon was probably due to the topic Parental involvement in homework of Hoover. Since parents had significant impacts on students' learning interests and career choice intention (Tey et al., 2020), their role toward students' homework was nonneglectable. Hoover's article provided crucial reviews and findings of parental involvement from other studies; thus, the article became popular throughout the years and across categories. The second-ranked author was $\mathrm{Xu}$, with 617 citations, and he was also the author with most documents in the corpus (46 articles). This author focused on topics such as homework management, homework purposes, self-regulation and emotion regulation of homework behavior. The last author in the top three was Trautwein, with a noticeable gap in the citations (437) compared to $\mathrm{Xu}$. Trautwein was interested in the homeworkachievement relationship, which the author used various variables (homework effort, homework frequency, homework motivation) to infer. In general, the most influential authors were mainly from the USA, Germany, and Portugal. Although China produced 55 documents (rank third in most productive countries), no Chinese author appeared in the table of most highly-cited authors. Conversely, an Israelis author entered the table, although this country produced only 16 documents, which was only one-third of the document number in China. The case in China 


\section{Table 2: Most highly-cited publications}

\begin{tabular}{|l|l|l|l|l|l|l|l|}
\hline Rank & Document & Year & Journal & Country & $\begin{array}{l}\text { Local } \\
\text { Citations }\end{array}$ & $\begin{array}{l}\text { Global } \\
\text { Citations }\end{array}$ & $\begin{array}{l}\text { Local } \\
\text { Citations (\%) }\end{array}$ \\
\hline 1 & COOPER H & 1998 & J EDUC PSYCHOL & USA & 94 & 211 & 44.55 \\
\hline 2 & TRAUTWEIN U & 2006 & J EDUC PSYCHOL & Germany & 86 & 226 & 38.05 \\
\hline 3 & EPSTEIN JL & 2001 & EDUC PSYCHOL & USA & 77 & 195 & 39.49 \\
\hline 4 & WARTON PM & 2001 & EDUC PSYCHOL & Australia & 74 & 130 & 56.92 \\
\hline 5 & TRAUTWEIN U & 2007 & LEARN INSTR & Germany & 68 & 143 & 47.55 \\
\hline 6 & HOOVER-DEMPSEY KV & 2001 & EDUC PSYCHOL-US & USA & 64 & 288 & 22.22 \\
\hline 7 & COOPER H & 2001 & EDUC PSYCHOL-US & USA & 61 & 128 & 47.66 \\
\hline 8 & XU JZ & 1998 & TEACH COLL REC & USA & 59 & 122 & 48.36 \\
\hline 9 & TRAUTWEIN U & 2003 & EDUC PSYCHOL REV & Germany & 51 & 124 & 41.13 \\
\hline 10 & XU JZ & 2005 & J EDUC RES & USA & 51 & 66 & 77.27 \\
\hline 11 & COOPER H & 1989 & EDUC LEADERSHIP & USA & 50 & 125 & 40.00 \\
\hline 12 & CORNO L & 2000 & ELEM SCHOOL J & USA & 50 & 90 & 55.56 \\
\hline 13 & COOPER H & 2000 & CONTEMP EDUC PSYCHOL & USA & 49 & 155 & 31.61 \\
\hline 14 & TRAUTWEIN U & 2002 & CONTEMP EDUC PSYCHOL & Germany & 46 & 108 & 42.59 \\
\hline 15 & XU JZ & 2008 & AM EDUC RES J & USA & 42 & 71 & 59.15 \\
\hline 16 & DETTMERS S & 2010 & J EDUC PSYCHOL & Germany & 39 & 79 & 49.37 \\
\hline 17 & KEITH TZ & 1982 & J EDUC PSYCHOL & USA & 38 & 90 & 42.22 \\
\hline 18 & ZIMMERMAN BJ & 2005 & CONTEMP EDUC PSYCHOL & USA & 38 & 183 & 20.77 \\
\hline 19 & CORNO L & 2004 & THEOR PRACT & USA & 37 & 64 & 57.81 \\
\hline 20 & XU JZ & 2003 & ELEM SCHOOL J & USA & 33 & 90 & 36.67 \\
\hline
\end{tabular}

and Israel proved that quantity did not coincide with quality.

Table 2 above shows 20 most locally cited documents, with their global citation index. Global citations are the number of citations a document has received from documents contained in the entire WoS database. Meanwhile, local citations are the number of citations a document has received from documents included in the analyzed collection (in our case the corpus includes 429 articles). We can see the impact of a document in the whole bibliographic database or the analyzed collection from these two indices. In our collection, Cooper et al. (1998) entitled "Relationships among attitudes about homework, amount of homework assigned and completed, and student achievement" was the most locally cited document with 94 citations. The study surveyed teachers, students and parents, then used path analysis to deduce the association between attitudes towards homework, homework quantity, homework completeness and academic achievement. The second-ranked in the list was "Predicting homework effort: Support for a domain-specific, multilevel homework model" ( 86 citations) by Trautwein et al. (2006), followed by the publication of Epstein and Van Voorhis (2001) named "More than minutes: Teachers' roles in designing homework" (77 citations).

However, when it comes to global citations, the result is slightly different. The most globally cited document was Hoover-Dempsey et al. (2001), named "Parental involvement in homework" (288 citations). Although this article was not the most cited by authors in the homework literature, it was the most recognized (among 429 
documents in the corpus) by WOS. The reason for a distinction between global citation and local citation might be the interdisciplinary character of the document. The second and third-ranked documents were Trautwein et al. (2006) with 226 citations and Cooper et al. (1998) with 211 citations. All in all, in the list of 20 documents, there are four documents of author Cooper, another four of author Trautwein and four from author $\mathrm{Xu}$. They are also the top three authors with the highest citation count (Table 1).

\subsection{Most Popular Research Topics}

Figures 5, 6 and 7 below are the results of coword analysis, or co-occurrence analysis, with the input data as "All Keywords" (including both author keywords and index keywords). Thesaurus file was used to reduce repetition among keywords such as "intervention" and "interventions" or "math" and "mathematics". Moreover, to avoid undesirable redundancy, the authors carefully considered all the synonyms and chose the most suitable word (Hallinger \& Kovačević, 2019).
For example, throughout the articles, keywords "parent homework involvement", "parent support", "parental involvement", and "parent participation" all indicated "family involvement" during students' doing homework process. As a result, the keyword "family involvement" was chosen as it could represent similar keywords, and the readers can see that, in total they accounted for a big part of research attention.

From the co-word map in Figure 5 above, one can see five noticeable clusters. Those research topics are primarily similar to ones found in Sharp et al. (2001). Although these clusters are not entirely clear-cut, they give us a general view of different literature favoured topics. The red cluster focuses on the effect of homework and its measurement, mainly on academic achievement. The relationship between homework and academic achievement has been inconsistent (Cooper et al., 2006; Rosário et al., 2018). One of the critical points was the inclusion of mediating or moderating variables (Trautwein, 2007). For example, Fan et al. (2017) reported that the

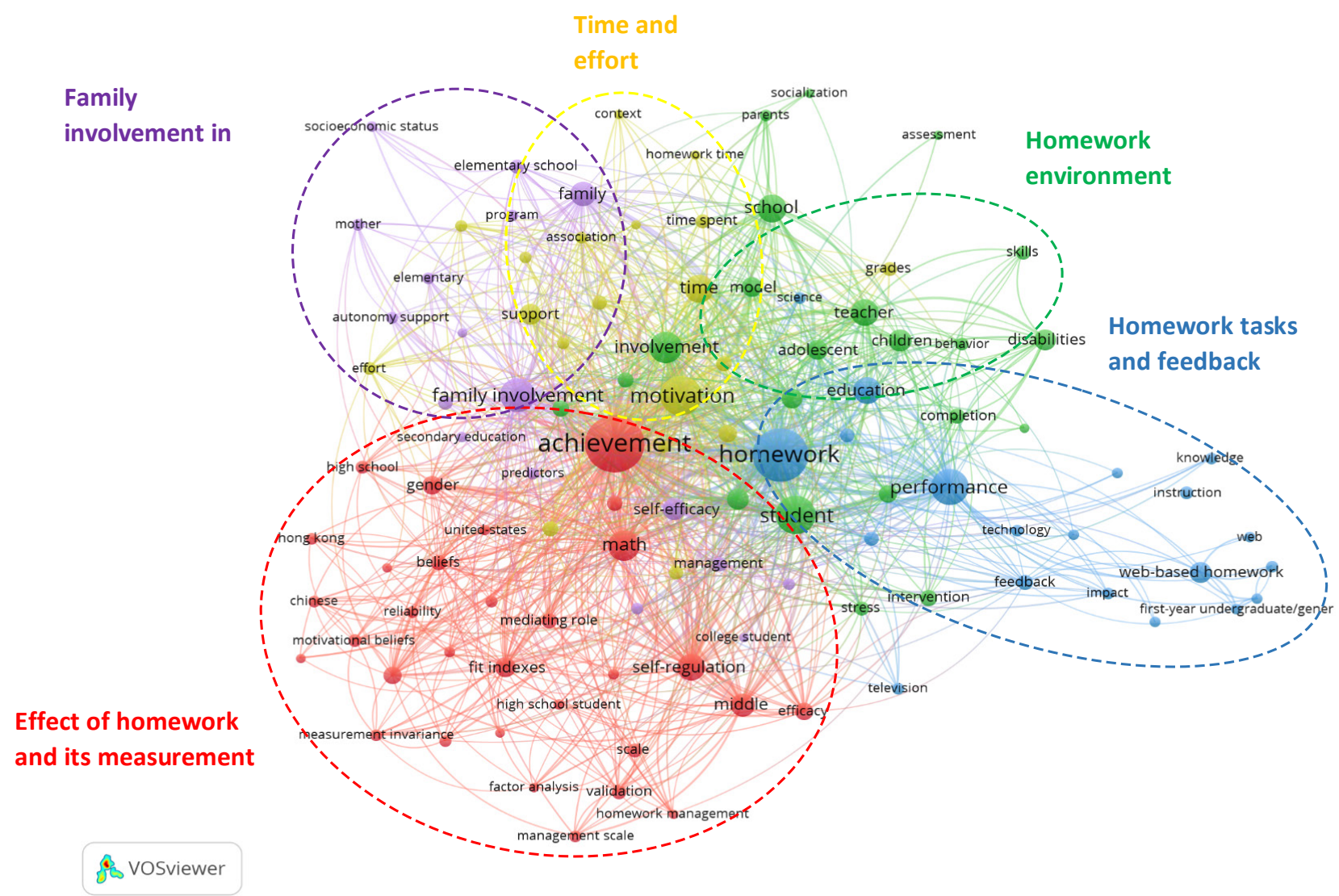

Figure 5: Co-occurrence of all keywords network of period 1977 -2020 
homework-achievement association is stronger in elementary schools (compared to secondary and high schools). Another example is the popular moderator: gender. In Cooper and colleagues' research (2006), the authors reported some studies that predict a higher effect of homework on achievement among female students (compared to male students). In addition, another reason for the mixed findings of the homework-achievement relationship is the difference in homework measurements. What measurement should be used to deduce the most exact homework-achievement relationship: time spent on homework, homework quality, homework quantity or homework effort? (Trautwein, 2007). The answer has not been settled, yet the discrepancies in effect were known.

The green cluster is centred around the research topic homework environment, including school, teacher, classroom, assessment, engagement. Both home and school environments can have big impacts on the homework process by creating a negative or positive atmosphere for students' learning (Cooper et al., 2006).

The blue cluster's focal point is homework tasks and feedback, with crucial keywords about instruction, feedback, system, technology and web-based. Many researchers investigated the impacts of homework feedback on students' achievement and how to use technology to help teachers give feedback without investing a considerable amount of time. For example, Cole and Todd (2003) used a "web-based multimedia homework" system to allow teachers to provide graded homework tasks with feedback quickly and easily. They also found that although the system did not affect students' performance, it produced positive attitudes (Cole \& Todd, 2003). Additionally, technological applications were not only helpful to the teachers, but also beneficial to students, as proved by the article "Generating an instructional video as homework activity is both effective and enjoyable" (Hoogerheide et al., 2019). Hoogerheide and colleagues allowed primary students to replace summarizing and restudying old lessons by teaching those lessons via videos. The results were fascinating, with students creating teaching videos reporting higher learning enjoyment levels and better test performance than those who restudied (Hoogerheide et al., 2019).

Other researchers, for example, Cunha et al. (2019) combined quantitative and qualitative methods to see if different homework feedback types influence 6th graders' engagement. Their findings reported that five types of homework feedback (checking homework completion, grading homework, checking homework on the board, praise, and constructive criticism) positively predicted students' emotional, behavioural and cognitive engagement. Moreover, those authors also confirmed a previous finding of Rosário et al. (2015) and Xu and Wu (2013), which was "detailed and personalized feedback is more beneficial for students than general feedback practices delivered to the whole class" (Cunha et al., 2019, p. 91). In the same direction, Núñez et al. (2015) suggested that homework feedback as perceived by students had positive impacts on the amount of homework completed, as well as the perceived quality of homework time management. Furthermore, they affirmed that students perceived a lower amount of teachers' homework feedback as they entered higher grade levels (Núñez et al., 2015).

The purple cluster's core is family involvement in homework, with the surrounding keywords are autonomy support, socioeconomic status, and mother. For some reason, scholars in our corpus researched more about mothers and maternal impacts on children' homework than about fathers (Sikiö et al., 2018; Viljaranta et al., 2018; LehnerMear, 2020). This favouritism toward mothers might be due to the fact that mother was more frequently involved in child-care (Levin et al., 1997), because of the distinction between Asian and European-American mothers, or just because the fathers' rate of providing answers was low (Sikiö et al., 2018). In addition to maternal effect, a recent favoured topic is parental autonomy support (Feng et al., 2019). In 1989, Grolnick and Ryan defined parental autonomy support as parental encouragement of children's independent choice-selecting, problem-solving, and decisionmaking (Grolnick \& Ryan, 1989). In the context of homework, parents' support for autonomy means giving support, hints and ideas when 
requested, discussing problems, guiding while honouring student's opinions and not solving problems for those students (Fei-Yin $\mathrm{Ng}$ et al., 2004). A study by Feng et al. (2019) reported that parental autonomy support perceived by middle school students positively impacted students' autonomous motivation, hence improved effort in mathematics homework. Another example of research in both autonomy support and maternal helping was the longitudinal study of Silinskas and Kikas (2019). This study indicated that a positive type of help with math homework - perceived (maternal) autonomy support - was associated with motivational aspects of academic outcomes (i.e., task persistence in homework situations). In particular, the more students received autonomy support from their mothers in Grade 6, the more persistent they were in completing homework in Grade 9. Unfortunately, the harmful type of help with homework - perceived control - was relatively stable than perceived autonomy support (Silinskas \& Kikas, 2019). The most popular article within this cluster would be "Parental involvement in homework", a review article by Hoover-Dempsey et al. (2001). The publication revealed critical findings regarding parents' motivation for involvement in homework, the content, mechanism and consequences of their involvement. The authors asserted that parental involvement was conducted via three main mechanisms (i.e. modelling, reinforcement, and instruction), positively predicting student achievement and some adjacent achievement attributes (e.g., attitudes toward homework, selfperception, self-regulation).

The final cluster, yellow, is dominated by time and effort as the highest appearing keywords are motivation, effort and time spent. In homework research, many scholars take the approach related to time spent on homework and its relation to achievement. Nevertheless, that relationship was inconsistent (Cooper et al., 2006). In 2009, Dettmers and colleagues studied 40 countries and found that homework time was positively related to mathematics achievement in most countries on the school level. However, on the student level, the relationship mentioned above was negative, meaning that students who spent more time on homework got lower grades on mathematics tests (Dettmers et al., 2009). Another interesting finding was the gender gap in homework time. Gershenson and Holt (2015) showed that, on average, males spent roughly 17 fewer minutes per day and about 1.25 fewer hours per week on homework than females. In addition to homework time, homework effort has increasingly been studied and considered an alternative measure of homework behaviour (Flunger et al., 2015). Homework effort is positively associated with academic achievement (Trautwein \& Lüdtke, 2007).

When combining both homework time and homework effort, Flunger and colleagues (2015) identified five learning types (i.e., fast learner, high-effort learner, average student, struggling learner, and minimalist). They suggested that large amounts of time spent on homework can positively predict students' achievement when the homework behavior involves high effort. Finally, a noticeable keyword in this yellow cluster is homework motivation. Motivation in homework had a close and complicated relationship with homework time and homework effort. In particular, some studies suggested that students' motivation and the time spent on homework had a positive relationship (Dettmers et al., 2009; Regueiro et al., 2014). Another study considered homework effort as an indicator of homework motivation (Hong et al., 2015), while some scholars indicated that homework motivation (including expectancy belief and value belief) could predict homework effort (Trautwein \& Lüdtke, 2009).

Before the 21st Century, homework literature had a limited number of documents and limited research topics. The most common research themes include (i) homework in the context of students with learning disabilities and special education; (ii) relationship between time spent on homework and academic achievement; (iii) homework under parents' perspectives and parent participation; and (iv) synthesis on homework. In Figure 5, those themes are reflected through most occurred keywords: "teacher" (11), "disabilities" (11), "achievement" (9), and "skills" (7).

Since 2001, the number of studies about 


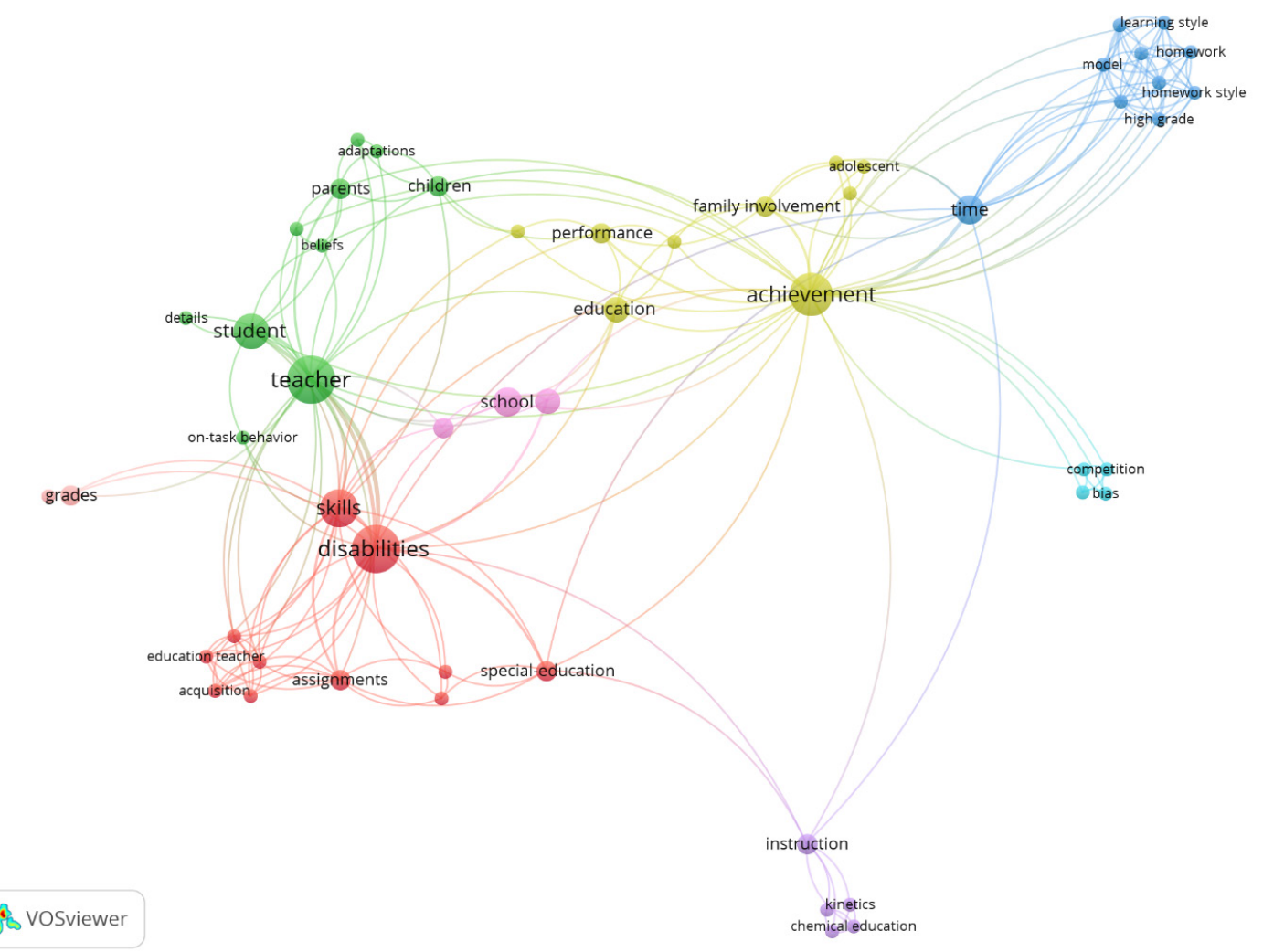

Figure 6: Co-occurrence network with all keywords from 1977 to 2000

(Number of occurrences of a keyword: 1; items 64)

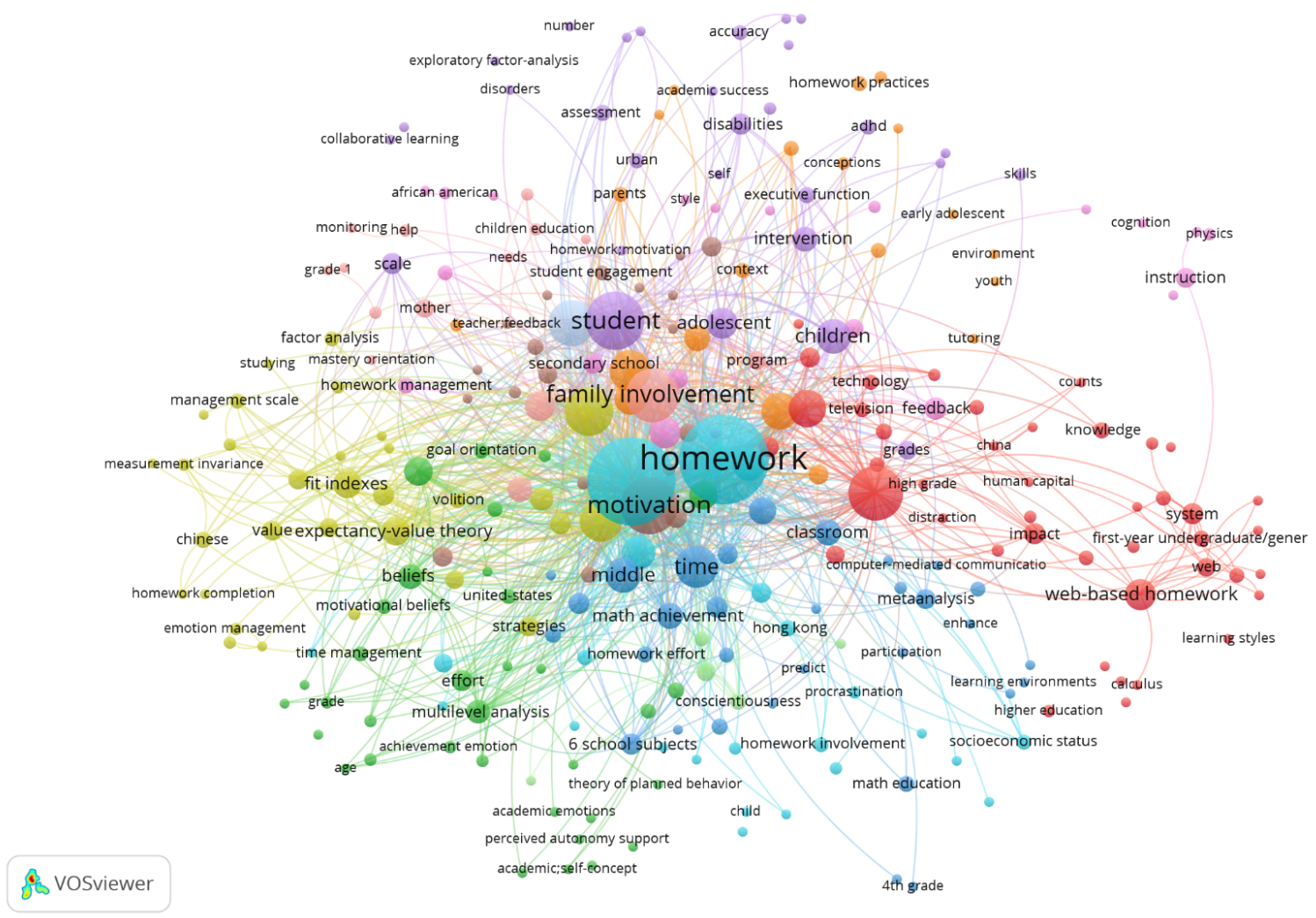

Figure 7: Co-occurrence network with all keywords from 2001 to 2020

(Number of occurrences of a keyword: 2; items 275) 
homework has increased remarkably; hence the variety of keywords also surged. In particular, the most common keywords are: "homework" (137), "achievement" (133), "motivation" (56), "performance" (52), "family involvement" (50), and "math" (41). Compared to the previous period, the $21^{\text {st }}$ century witnessed less literature about homework-related to students' disabilities and more about students' self-regulation, selfefficacy and motivation of homework behaviors. Homework's influence on performance and achievement still accounted for most homework research, followed by parental involvement or family help with homework. A great amount of research focused on gender differences, webbased and traditional homework comparison. Also, considerable literature concentrated on validating homework scales (purpose, management, feedback) or investigating data analysis-related issues (reliability, mediating role, fit indexes). Regarding research subjects, many studies examined math and science homework related problems.

\section{Conclusion, Implications and Limitation}

In conclusion, this study used bibliometric data analysis to document the growth trajectory, key authors, publications, and homework research topics. Regarding the first research question, homework literature increased gradually in volume, with most publications originating from the United States of America. However, the number of documents could not reflect precisely the quality or citation count in that country. Sometimes the less (number of documents) is more (number of citations). Additionally, all publications appeared mainly in psychology and educational research journals, yet the journal with the most documents was the Journal of Chemical Education. This fact suggested that Chemistry was the focus of homework research among science subjects, especially with technology engagement at the undergraduate level. The second research question is answered when considering both authors' number of publications and citations. Critical authors in this knowledge base include Cooper, $\mathrm{Xu}$, and Trautwein. Cooper was famous for the definition of homework as well as many systematic review and synthesis articles. Meanwhile, Xu JZ was the scholar with the highest number of homework articles, and Trautwein was the new emerging scholar since the 21 st century with many articles about homework effort.

In response to the last question, our coword analysis illustrates five popular research topics, namely the effect of homework and its measurement, homework environment, homework tasks and feedback, family involvement in homework, and time and effort. Those topics appeared distinctively in two periods - before and from 2000, yet the main studied topic throughout the two periods was the relationship between homework time or homework effort and academic performance or academic achievement. Finally, it can be seen from the results analysis of this study, homework is essential for educators, for students, and for parents. Homework affects the way teachers teach, the way students learn, and the way parents communicate. Homework can change students' motivation, attitudes and efforts, as well as improve their self-regulation, self-efficacy, and self-perception. The famous homework-academic achievement association is just a minor positive part amongst all the perks of homework.

This research still has some caveats that future research can improve. First, this review was limited to the document type (articles) and the English documents in the homework literature; hence it provided an incomplete picture of homework knowledge and scholars. Further studies can examine other languages publications and use various analysis tools (such as bibliometrics and scientometrics) with various techniques to enhance the depth and the transparency of this topic (Vuong, 2020). Second, the corpus was taken only from the WOS database, which targets top-tier journals and publications. Therefore, the amount of analyzed literature has been limited to high-impact publications only. On the one hand, it secured the quality of this study. On the other hand, it also limits the current findings from emerging contexts and other kinds of publications such as technical reports or working papers. Thus, we suggest that future 
research might consider a larger pool of data like Scopus and apply a protocol to include qualified working papers and technical reports. Finally, our study adopted a horizontal approach that analyzed publications according to geographics, periods, and keyword clusters (Vuong et al., 2020). Therefore, future studies are suggested to take a vertical approach and analyze deeper into niche topics and publications track of authors.

This study's results can be used as the foundation for future researchers to dig deeper into one specific topic in homework literature. It is also essential for practitioners when considering homework related policies and student-teachers-parents' relationships in the academic environment. Since scholars found that the homework-academic achievement relationship was more substantial in elementary school (Rosário et al., 2018; Fan et al., 2017),

\section{References}

Aria, M., \& Cuccurullo, C. (2017). bibliometrics : An R-tool for comprehensive science mapping analysis. Journal of Informetrics, 11(4), 959-975. https://doi. org/10.1016/j.joi.2017.08.007

Baş, G., Şentürk, C., \& Ciğerci, F. M. (2017). Homework and academic achievement: A meta-analytic review of research. Educational Research, 27(1), 31-50. https://search.informit.org/doi/10.3316/ ielapa.788266292838086

Cole, R. S., \& Todd, J. B. (2003). Effects of Web-Based Multimedia Homework with Immediate Rich Feedback on Student Learning in General Chemistry. Journal of Chemical Education, 80(11), 1338. https:// doi.org/10.1021/ed080p1338

Cooper, H. (1989). Synthesis of research on homework. Educational Leadership, 47(3), 85-91.

Cooper, H. (1994). Homework research and policy: A review of the literature. Research/Practice, 2(2), $1-10$.

Cooper, H., Lindsay, J. J., Nye, B., \& Greathouse, S. (1998). Relationships among attitudes about homework, amount of homework assigned and completed, and student achievement. Journal of Educational Psychology, 90(1), 70-83. https://doi. org/10.1037/0022-0663.90.1.70

Cooper, H., Robinson, J. C., \& Patall, E. A. (2006). Does homework improve academic achievement? A Synthesis of Research, 1987 - 2003. Review of Educational Research, 76(1), 1-62.

Corno, L. (2000). Looking at Homework Differently. The Elementary School Journal, 100(5), 529-548. https:// school administrators and teachers can consider including homework as a prominent part of formal education. Moreover, policymakers should pay attention to new roles of homework and many facets of social life, possibly altering both the homework process and outcome (Corno, 2000). In summary the authors suggest that, the fulcrum of homework has yet to be defined. However, it is highly likely a combination of curriculum (and even extracurricular) plan, students' perception of homework quality, parents' autonomy support, and teachers' effort to match the homework characteristics to students' learning needs (Rosário et al., 2018; Fitzmaurice et al., 2020), to name a few. Consequently, more homeworkrelated variables should be studied more carefully and thoroughly as it is not simple for teachers to write down on the board "Homework" and then tell the students ", You have to do it because it is good for you!”.

\section{doi.org/10.1086/499654}

Cretu, D. M., \& Morandau, F. (2020). Initial teacher education for inclusive education: A bibliometric analysis of educational research. Sustainability (Switzerland), 12(12). https://doi.org/10.3390/ SU12124923

Cunha, J., Rosário, P., Núñez, J. C., Vallejo, G., Martins, J., \& Högemann, J. (2019). Does teacher homework feedback matter to 6th graders' school engagement?: a mixed-methods study. Metacognition and Learning, 14(2), 89-129. https://doi.org/10.1007/s11409-01909200-z

Dettmers, S., Trautwein, U., \& Lüdtke, O. (2009). The relationship between homework time and achievement is not universal: evidence from multilevel analyses in 40 countries. School Effectiveness and School Improvement, 20(4), 375-405. https://doi. org/10.1080/09243450902904601

Epstein, J. L., \& Van Voorhis, F. L. (2001). More Than Minutes: Teachers' Roles in Designing Homework. Educational Psychologist, 36(3), 181-193. https:// doi.org/10.1207/S15326985EP3603_4

Fan, H., Xu, J., Cai, Z., He, J., \& Fan, X. (2017). Homework and students' achievement in math and science: A 30-year meta-analysis, 1986-2015. Educational Research Review, 20, 35-54. https://doi. org/10.1016/j.edurev.2016.11.003

Fei-Yin Ng, F., Kenney-Benson, G. A., \& Pomerantz, E. M. (2004). Children's Achievement Moderates the Effects of Mothers' Use of Control and Autonomy Support. Child Development, 75(3), 764-780. https:// 
doi.org/10.1111/j.1467-8624.2004.00705.X

Feng, X., Xie, K., Gong, S., Gao, L., \& Cao, Y. (2019). Effects of Parental Autonomy Support and Teacher Support on Middle School Students' Homework Effort: Homework Autonomous Motivation as Mediator. Frontiers in Psychology, 10. https://doi. org/10.3389/fpsyg.2019.00612

Fitzmaurice, H., Flynn, M., \& Hanafin, J. (2020). Primary teachers' homework practices: Identity, expectations, policies and cultural values. Issues in Educational Research, 30(3), 897-919. http://www.iier.org.au/ iier30/fitzmaurice.pdf

Flunger, B., Trautwein, U., Nagengast, B., Lüdtke, O., Niggli, A., \& Schnyder, I. (2015). The Janus-faced nature of time spent on homework: Using latent profile analyses to predict academic achievement over a school year. Learning and Instruction, 39, 97-106. https://doi.org/10.1016/j.learninstruc.2015.05.008

Gershenson, S., \& Holt, S. B. (2015). Gender Gaps in High School Students' Homework Time. Educational Researcher, 44(8), 432-441. https://doi. org/10.3102/0013189X15616123

Gill, B., \& Schlossman, S. (2000). The Lost Cause of Homework Reform. American Journal of Education, 109(1), 27-62. https://doi.org/10.1086/444258

Grolnick, W. S., \& Ryan, R. M. (1989). Parent styles associated with children's self-regulation and competence in school. Journal of Educational Psychology, 81(2), 143-154. https://doi. org/10.1037/0022-0663.81.2.143

Hallam, S., \& Rogers, L. (2018). Homework: The Evidence. UCL IOE Press. UCL Institute of Education, University of London, 20 Bedford Way, London WC1H 0AL.

Hallinger, P., \& Chatpinyakoop, C. (2019). A Bibliometric Review of Research on Higher Education for Sustainable Development, 1998-2018. Sustainability, 11(8), 2401. https://doi.org/10.3390/su11082401

Hallinger, P., \& Kovačević, J. (2019). A Bibliometric Review of Research on Educational Administration: Science Mapping the Literature, 1960 to 2018. Review of Educational Research, 89(3), 335-369. https://doi. org $/ 10.3102 / 0034654319830380$

Hoang, A.-D., Pham, H.-H., Nguyen, Y.-C., Nguyen, L.K.-N., Vuong, Q.-H., Dam, M. Q., Tran, T., \& Nguyen, T.-T. (2020). Introducing a tool to gauge curriculum quality under Sustainable Development Goal 4: The case of primary schools in Vietnam. International Review of Education. https://doi.org/10.1007/s11159020-09850-1

Hong, E., Mason, E., Peng, Y., \& Lee, N. (2015). Effects of homework motivation and worry anxiety on homework achievement in mathematics and English. Educational Research and Evaluation, 21(7-8), 491514. https://doi.org/10.1080/13803611.2015.1131721

Hoogerheide, V., Visee, J., Lachner, A., \& van Gog, T. (2019). Generating an instructional video as homework activity is both effective and enjoyable. Learning and Instruction, 64, 101226. https://doi. org/10.1016/j.learninstruc.2019.101226

Hoover-Dempsey, K. V., Battiato, A. C., Walker, J. M. T., Reed, R. P., DeJong, J. M., \& Jones, K. P. (2001). Parental Involvement in Homework. Educational Psychologist, 36(3), 195-209. https://doi.org/10.1207/ S15326985EP3603_5

Lehner-Mear, R. (2020). Good mother, bad mother? Maternal identities and cyber-agency in the primary school homework debate. Gender and Education, 1-21. https://doi.org/10.1080/09540253.2020.17639 20

Levin, I., Levy-Shiff, R., Appelbaum-Peled, T., Katz, I., Komar, M., \& Meiran, N. (1997). Antecedents and consequences of maternal involvement in children's homework: A longitudinal analysis. Journal of Applied Developmental Psychology, 18(2), 207-227. https://doi.org/10.1016/S0193-3973(97)90036-8

Li, K., Rollins, J., \& Yan, E. (2018). Web of Science use in published research and review papers 1997-2017: a selective, dynamic, cross-domain, content-based analysis. Scientometrics, 115(1), 1-20. https://doi. org/10.1007/s11192-017-2622-5

Magalhães, P., Ferreira, D., Cunha, J., \& Rosário, P. (2020). Online vs traditional homework: A systematic review on the benefits to students' performance. Computers \& Education, 152, 103869. https://doi.org/10.1016/j. compedu.2020.103869

Marzano, R. J., \& Pickering, D. J. (2007). The case for and against homework. Educational Leadership, 64(6), 74-79.

Moher, D., Liberati, A., Tetzlaff, J., \& Altman, D. G. (2010). Preferred reporting items for systematic reviews and meta-analyses: The PRISMA statement. International Journal of Surgery, 8(5), 336-341. https://doi.org/10.1016/j.ijsu.2010.02.007

Núñez, J. C., Suárez, N., Rosário, P., Vallejo, G., Cerezo, R., \& Valle, A. (2015). Teachers' Feedback on Homework, Homework-Related Behaviors, and Academic Achievement. The Journal of Educational Research, 108(3), 204-216. https://doi.org/10.1080/0 0220671.2013 .878298

OECD. (2014). Does homework perpetuate inequities in education? In OECD Publishing. https://doi.org/ https://doi.org/10.1787/5jxrhqhtx2xt-en

Otto, W. (1985). Homework: A Meta-Analysis. Journal of Reading, 28(8), 764-766. https://www.jstor.org/ stable/40029606

Regueiro, B., Suárez, N., Valle, A., Núñez, J. C., \& Rosário, P. (2014). Homework Motivation and Engagement throughout Compulsory Education // La motivación e implicación en los deberes escolares a lo largo de la escolaridad obligatoria. Revista de Psicodidactica / Journal of Psychodidactics, 20(1), 47-63. https://doi. org/10.1387/RevPsicodidact.12641

Rosário, P., Carlos Núñez, J., Vallejo, G., Nunes, T., 
Cunha, J., Fuentes, S., \& Valle, A. (2018). Homework purposes, homework behaviors, and academic achievement. Examining the mediating role of students' perceived homework quality. Contemporary Educational Psychology, 53, 168-180. https://doi. org/10.1016/j.cedpsych.2018.04.001

Rosário, P., Núñez, J. C., Vallejo, G., Cunha, J., Nunes, T., Suárez, N., Fuentes, S., \& Moreira, T. (2015). The effects of teachers' homework follow-up practices on students' EFL performance: a randomized-group design. Frontiers in Psychology, 6. https://doi. org/10.3389/fpsyg.2015.01528

Sharp, C., Benefield, P., \& Keys, W. (2001). Homework: a Review of Recent Research. National Foundation for Educational Research. https://www.nfer.ac.uk/ publications/hwk01/hwk01.pdf

Sikiö, R., Siekkinen, M., Holopainen, L., Silinskas, G., Lerkkanen, M.-K., \& Nurmi, J.-E. (2018). Maternal parenting styles, homework help, and children's literacy development in language minority and Finnish-speaking families. European Journal of Psychology of Education, 33(2), 235-250. https://doi. org/10.1007/s10212-017-0330-4

Silinskas, G., \& Kikas, E. (2019). Math homework: Parental help and children's academic outcomes. Contemporary Educational Psychology, 59, 101784. https://doi.org/10.1016/j.cedpsych.2019.101784

Tey, T. C. Y., Moses, P., \& Cheah, P. K. (2020). Teacher, parental and friend influences on STEM interest and career choice intention. Issues in Educational Research, 30(4), 1558-1575. http://www.iier.org.au/ iier30/tey.pdf

Tran, T., Hoang, A.-D., Nguyen, Y.-C., Nguyen, L.-C., Ta, N.-T., Pham, Q.-H., Pham, C.-X., Le, Q.-A., Dinh, V.-H., \& Nguyen, T.-T. (2020). Toward sustainable learning during school suspension: Socioeconomic, occupational aspirations, and learning behavior of vietnamese students during COVID-19. Sustainability (Switzerland), 12(10). https://doi.org/10.3390/ su12104195

Trautwein, U. (2007). The homework-achievement relation reconsidered: Differentiating homework time, homework frequency, and homework effort. Learning and Instruction, 17(3), 372-388. https://doi. org/10.1016/j.learninstruc.2007.02.009

Trautwein, U., \& Lüdtke, O. (2007). Students' selfreported effort and time on homework in six school subjects: Between-students differences and withinstudent variation. Journal of Educational Psychology, 99(2), 432-444. https://doi.org/10.1037/00220663.99 .2 .432
Trautwein, U., \& Lüdtke, O. (2009). Predicting homework motivation and homework effort in six school subjects: The role of person and family characteristics, classroom factors, and school track. Learning and Instruction, 19(3), 243-258. https://doi.org/10.1016/j. learninstruc.2008.05.001

Trautwein, U., Lüdtke, O., Schnyder, I., \& Niggli, A. (2006). Predicting homework effort: Support for a domain-specific, multilevel homework model. Journal of Educational Psychology, 98(2), 438-456. https://doi.org/10.1037/0022-0663.98.2.438

Viljaranta, J., Silinskas, G., Lerkkanen, M.-K., Hirvonen, R., Pakarinen, E., Poikkeus, A.-M., \& Nurmi, J.-E. (2018). Maternal homework assistance and children's task-persistent behavior in elementary school Learning and Instruction, 56, 54-63. https://doi. org/10.1016/j.learninstruc.2018.04.005

Vuong, Q.-H. (2018). The (ir)rational consideration of the cost of science in transition economies. Nature Human Behaviour, 2(1), 5-5. https://doi.org/10.1038/ s41562-017-0281-4

Vuong, Q.-H. (2020). Reform retractions to make them more transparent. Nature, 582(7811), 149-149. https://doi.org/10.1038/d41586-020-01694-x

Vuong, Q.-H., Do, M.-T., Pham, T.-V.-A., Do, T.-A., Doan, P.-T., Hoang, A.-D., Ta, T.-H., Le, Q.-A., \& Pham, H.-H. (2020). The status of educational sciences in Vietnam: A bibliometric analysis from Clarivate Web of Science database between 1991 and 2018. Problems of Education in the 21st Century, 78(4), 644-662. https://doi.org/10.33225/pec/20.78.644

Vuong, Q.-H., Napier, N. K., Ho, T. M., Nguyen, V. H., Vuong, T.-T., Pham, H. H., \& Nguyen, H. K. T. (2019). Effects of work environment and collaboration on research productivity in Vietnamese social sciences: evidence from 2008 to 2017 Scopus data. Studies in Higher Education, 44(12), 2132-2147. https://doi.org /10.1080/03075079.2018.1479845

Walker, J. M. T., Hoover-Dempsey, K. V., Whetsel, D. R., \& Green, C. L. (2004). parental involvement in homework: A review of current research and its implications for teachers, after school program staff, and parent leaders. https://inside.sou.edu/assets/edhealth/education/docs/ecd/ParentInvolveHomework pdf

Xu, J., \& Wu, H. (2013). Self-Regulation of homework Behavior: Homework management at the secondary school level. The Journal of Educational Research, 106(1), 1-13. https://doi.org/10.1080/00220671.2012 .658457 